\title{
FECHAMENTO E ÍNDICE DE ÁREA FOLIAR DA CULTURA DA SOJA EM DIFERENTES ARRANJOS ESPACIAIS $\left({ }^{1}\right)$
}

\author{
LÍLIA SICHMANN HEIFFIG $\left({ }^{2}\right)$; GIL MIGUEL DE SOUSA CÂMARA $\left({ }^{2}\right)$; LUCIANA APARECIDA \\ MARQUES $\left({ }^{2}\right)$; DANIEL BOTELHO PEDROSO $\left({ }^{2}\right)$; SÔNIA MARIA DE STÉFANO PIEDADE $\left({ }^{3}\right)$
}

\begin{abstract}
RESUMO
O experimento teve por objetivo avaliar o tempo de fechamento das entrelinhas e o índice de área foliar da cultura da soja (Glycine max (L.) Merrill), com a identificação do arranjo populacional mais adequado ao manejo da cultivar MG/BR 46 (Conquista) com alta produtividade agrícola. O experimento foi desenvolvido em área experimental da Escola Superior de Agricultura "Luiz de Queiroz" (ESALQ/ USP), no município de Piracicaba (SP), durante o ano agrícola de 2001/2002. Os 30 tratamentos, delineados em blocos ao acaso com parcelas subdivididas e com três repetições, constaram de diferentes arranjos espaciais, obtidos pela combinação de seis espaçamentos entre linhas $(0,20 ; 0,30 ; 0,40 ; 0,50 ; 0,60$ e $0,70 \mathrm{~m})$ e cinco populações $(70.000 ; 140.000 ; 210.000 ; 280.000$ e 350.000 plantas/ha). As características avaliadas foram: tempo de fechamento de entrelinhas; índice de área foliar e produtividade agrícola. Concluiu-se que: a) Na cultivar Conquista, semeada em linhas espaçadas entre si de 0,20 a 0,60 m, o índice de área foliar é máximo no estádio fenológico correspondente ao início de granação das vagens $\left(R_{5}\right)$; b) $O$ índice de área foliar é aumentado proporcionalmente com o aumento da população de plantas; c) o fator de mais influência na velocidade no fechamento entrelinhas é o espaçamento.
\end{abstract}

Palavras-chave: densidade de semeadura, espaçamento entre linhas, cobertura do solo, dossel cultural.

\section{ABSTRACT \\ CLOSED CANOPY AND LEAF AREA INDEX OF SOYBEAN IN DIFFERENT SPACE ARRANGEMENTS}

This research had the purposes to evaluate the time to achieve closed canopy and leaf area index of soybean (Glycine max (L.) Merrill) and identify the best space arrangements for higher grain yields of cultivar MG/BR 46 (Conquista). The experiment was carried out at the experimental fields of Escola Superior de Agricultura "Luiz de Queiroz" (USP/ESALQ), São Paulo State University, in Piracicaba, State of São Paulo, Brazil, during the 2001/2002 growing season. The 30 treatments consisted of different space arrangements, combining 6 row spacing $(0.20 ; 0.30 ; 0.40 ; 0.50 ; 0.60 ; 0.70 \mathrm{~m})$ with 5 different populations $\left(70,000 ; 140,000 ; 210,000 ; 280,000 ; 350,000\right.$ plants ha $\left.^{-1}\right)$, in a complete randomized blocks design with subdivided plots and three replications. The evaluated characteristics were: time to achieve closed canopy; leaf area index and grain yield. The conclusions are: a) in the cultivar MG/BR - 46 (Conquista) cultivated under 0.20 to $0.60 \mathrm{~m}$ row spacing, the leaf area index maximum is at the beginning of seed-filling stage $\left(R_{5}\right)$; b) the leaf area index becomes higher proportionally with the increase of population; c) the factor that more influenced to shorten the time to achieve closed canopy was the spacement.

Key words: sowing density, row spacing, soil covering, crop canopy.

( $\left.{ }^{1}\right)$ Parte da Dissertação de Mestrado da primeira autora apresentada à Escola Superior de Agricultura "Luiz de Queiroz", Piracicaba (SP). Projeto financiado pela FAPESP. Recebido para publicação em 31 de março de 2005 e aceito em 28 de abril de 2006.

( $\left.{ }^{2}\right)$ Departamento de Produção Vegetal da ESALQ/USP, Av. Pádua Dias, 11, 13418-970 Piracicaba (SP). Autora correspondente. E-mail: 1sheiffi@esalq.usp.br

$\left(^{3}\right)$ Departamento de Ciências Exatas, ESALQ/USP, Piracicaba (SP). 


\section{INTRODUÇÃO}

Teoricamente, para ser atingido o potencial máximo de produção em uma planta, é necessário que se tenham as melhores condições de solo e clima, com o mínimo de competição. Em estudos sobre arranjo de plantas com novas disposições na lavoura permitese minimizar a competição intraespecífica e maximiza-se o aproveitamento dos recursos ambientais. As modificações no arranjo podem ser feitas por meio da variação do espaçamento entre as plantas na linha de semeadura e da distância entre linhas (Pires et al., 1998). Na soja se tem tolerância a uma ampla variação na população de plantas, alterando-se mais sua morfologia que o rendimento de grãos (BARNI et al., 1985; GAUDÊNCIO et al., 1990). O menor efeito na população de soja se deve à capacidade de compensação no uso do espaço entre plantas (Реіхото et al., 2000).

O rendimento máximo da soja é determinado pela otimização da capacidade da planta na interceptação da radiação solar e ou acúmulo de matéria seca durante o estádio vegetativo e o reprodutivo, sendo neste último, dependente, também, de outros fatores como condições meteorológicas, data de semeadura, genótipo, fertilidade do solo, população de plantas e espaçamento entre linhas (Wells, 1991 e 1993).

Um dos objetivos da modificação no arranjo de plantas, pela redução da distância entre linhas, é a diminuição do tempo para que a interceptação pela cultura seja de $95 \%$ da radiação solar incidente, e com isso, incrementa-se a quantidade de luz captada por unidade de área e de tempo (Board e Harville, 1992; Shaw e Weber, 1967). O índice de área foliar (IAF) é a relação entre a área da folhagem e a superfície do solo por ela ocupada e é variável de acordo com espécies vegetais, clima, estações do ano e estádio de desenvolvimento da planta (MÜLler, 1981; CÂMARA e HeIfFIG, 2000).

Com o aumento do IAF, até um valor crítico, também se aumenta a interceptação de luz e, conseqüentemente, a fotossíntese líquida. O "IAF crítico" é definido como a quantidade de folha requerida para interceptação de $95 \%$ da radiação solar ao meio dia. Quando a taxa de crescimento é decrescente, abaixo de um dado IAF e, não havendo mais uma contribuição líquida ao acúmulo de fotossintetizados, será denominado "IAF ótimo" (MÜLLER, 1981).

Com a redução no espaçamento entre linhas podem ser acarretadas modificações na quantidade de matéria seca acumulada pelas plantas, fechamento da área da entrelinha (ScotT e AldRICH, 1975), área foliar e índice de área foliar, que podem resultar em aumento no rendimento de grãos (PIRES et al., 1998). Com a alteração da área foliar, devido à densidade de população e tipo de planta, aumentam a percentagem de interceptação da radiação solar e o acúmulo de matéria seca a valores máximos, à medida que a área foliar é incrementada (PorRAs et al., 1997).

Como estratégia para redução dos custos de produção, alguns produtores vêm diminuindo o espaçamento entre as linhas da cultura, bem como as doses e o número de aplicações de herbicidas, a fim de permitir a eficiência cultural no processo de competição com as plantas daninhas. Ao reduzir o espaçamento entrelinhas, sem o devido ajuste da densidade de plantas na linha, o produtor poderá contribuir para o acamamento das plantas. Por outro lado, se o ajuste da densidade resultar em poucas plantas por metro, as cultivares poderão ter menor crescimento em altura e mais ramificações, entretanto, maior probabilidade de aumento de perdas na colheita, reduzindo-se a produção.

Em função dos fatos expostos, desenvolveu-se o presente trabalho, cujos principais objetivos foram avaliar a adaptação da planta de soja aos diferentes arranjos espaciais (plasticidade) e identificar o arranjo espacial que mais bem representasse ou possibilitasse associar o manejo de uma cultivar moderna com alta produtividade agrícola. As hipóteses do presente projeto são as seguintes: (a) A cultura da soja tem alta plasticidade, e (b) Para cada combinação "espaçamento entre linhas x densidade de plantas na linha" existe um valor ótimo para população de plantas com o qual se possibilita maior produtividade de grãos.

\section{MATERIAL E MÉTODOS}

O experimento foi realizado em área experimental da Escola Superior de Agricultura "Luiz de Queiroz" (ESALQ/USP), no município de Piracicaba (SP), localizada a $22^{\circ} 41^{\prime} 30^{\prime \prime}$ de latitude Sul, $47^{\circ} 38^{\prime} 30^{\prime \prime}$ de longitude Oeste e $546 \mathrm{~m}$ de altitude. A instalação do experimento ocorreu em 4 de dezembro de 2001, colhendo-se as parcelas em 26 de abril de 2002. Foi utilizada a cultivar MG/BR - 46 (Conquista), por se tratar de uma das mais cultivadas no Brasil, especialmente nos Estados do Sudeste e Centro-Oeste.

O solo da área experimental é classificado como Latossolo Vermelho Distrófico argiloso, profundo, com boa drenagem e textura muito argilosa. A adubação de base foi dimensionada em função dos resultados da análise química e da produtividade da cultivar, estimada para $2.500 \mathrm{~kg} \mathrm{ha}^{-1}$. Aplicou-se o 
equivalente a $300 \mathrm{~kg} \mathrm{ha}^{-1}$ da fórmula fertilizante 00 20-20, correspondendo a $60 \mathrm{~kg}$ de $\mathrm{P}_{2} \mathrm{O}_{5}$ e $60 \mathrm{~kg} \mathrm{~K} \mathrm{~K}_{2} \mathrm{O}$, tendo-se como fontes, superfosfato simples e cloreto de potássio respectivamente. O nitrogênio foi fornecido pela fixação simbiótica do $\mathrm{N}_{2}$, via inoculação das sementes, com inoculante turfoso, na dose equivalente a $250 \mathrm{~g}$ por $50 \mathrm{~kg}$ de sementes.

Adotou-se o delineamento experimental em blocos ao acaso com parcelas subdivididas com três repetições, constando de seis níveis do fator espaçamento entre linhas $(0,20 ; 0,30 ; 0,40 ; 0,50 ; 0,60$ e $0,70 \mathrm{~m}$ ) (parcelas) e cinco níveis do fator população de plantas $(70.000 ; 140.000 ; 210.000 ; 280.000$ e 350.000 plantas/ha) (subparcelas), resultando em 30 arranjos espaciais (tratamentos). O número de linhas por unidade experimental foi variável, conforme a combinação entre espaçamentos e densidades de plantas na linha. As populações finais de plantas para cada tratamento foram obtidas por meio de desbaste.

Em solo preparado convencionalmente, as parcelas foram instaladas por meio de sulcação, de aproximadamente $0,10 \mathrm{~m}$, para distribuição dos fertilizantes, sendo, em seguida, as sementes, previamente tratadas com fungicida e submetidas à inoculação com estirpes de Bradyrhizobium japonicum, distribuídas manualmente a $0,05 \mathrm{~m}$ de profundidade, por meio de réguas de semeadura, respeitando-se para cada parcela, a respectiva densidade de semeadura sorteada. Feita a semeadura, os sulcos foram cobertos com terra.

O fungicida utilizado no tratamento das sementes de soja foi o thiran + thiabendazole, na dose recomendada de $70+17 \mathrm{~g}$ de i.a. por $100 \mathrm{~kg}$ de sementes, respectivamente. Como a área experimental possui histórico de soja inoculada, as sementes receberam inoculante turfoso esterilizado na dose equivalente a $400 \mathrm{~g} / 40 \mathrm{~kg}$ de sementes.

A área experimental foi sistematicamente monitorada por meio de visitas rotineiras para a coleta de dados. Na medida em que foram necessários, adotaram-se os tratos culturais e o controle fitossanitário recomendados para a cultura da soja.

Identificada a maturidade de campo, foram realizadas as últimas coletas de dados e providenciada a colheita nas áreas úteis de cada parcela, por meio de roçadora costal motorizada munida de disco rotativo com 80 dentes. Após a trilha mecanizada das plantas, as sementes foram limpas e acondicionadas em sacos de papel e encaminhadas ao laboratório para avaliação da produtividade agrícola.
As características avaliadas foram: tempo para cobertura da área nas entrelinhas, associado à avaliação semanal da área percentual coberta pela folhagem, considerando-se como $100 \%$ de fechamento, a metade da entrelinha coberta pelas folhas de cada linha adjacente, com o auxílio de uma régua graduada; índice de área foliar, obtido por meio da utilização de integrador de área foliar LI-COR modelo LAI 2000, produtividade agrícola e massa de mil grãos (BRASIL, 1992).

\section{RESULTADOS E DISCUSSÃO}

Os dados obtidos de radiação solar total, precipitação pluvial total e média estão relacionados na tabela 1. Observam-se as variações de temperatura média diária do ar e de precipitação pluvial ao longo de 143 dias de ciclo, da semeadura à colheita, da cultivar Conquista (Figura 1).

Na fase reprodutiva, observa-se, na tabela 1 , o aumento na disponibilidade de energia para o ambiente de experimentação, tanto da radiação solar, como de temperaturas. Para os 60 dias de fase vegetativa mais intensa, a disponibilidade média diária de energia na forma de radiação solar foi de 410,6 cal cm $\mathrm{cm}^{-2} \mathrm{dia}^{-1}$. Para os 83 dias de fase reprodutiva, a disponibilidade média diária de energia foi de $587,5 \mathrm{cal} \mathrm{cm}^{-2} \mathrm{dia}^{-1}$, associada também, aos maiores valores de energia térmica.

Constata-se diminuição da disponibilidade de água nas fases fisiológicas do florescimento e frutificação da soja, até o início da granação (estádio $R_{5}$ ). A partir desse último estádio, iniciado em 7 de março de 2002, constatou-se também a precipitação pluvial total de $255 \mathrm{~mm}$, porém, mal distribuída, comprometendo os estádios intermediários e finais da granação (Figura 1).

Dessa forma, essa menor precipitação pluvial na fase mediana e final da formação dos grãos, poderia justificar as produtividades agrícolas observadas em níveis aquém da produtividade média esperada para a cultivar Conquista.

$\mathrm{Na}$ análise da variância, para a variável tempo de fechamento nas entrelinhas, foram obtidos valores de $F$ significativos para os fatores espaçamento entre linhas e população de plantas para todos os estádios fenológicos avaliados: $V_{7}, V_{9} / R_{1}, R_{2}, R_{3}, R_{5}, R_{5} / R_{6}$ e $R_{6 .}$. Com relação à interação dos fatores espaçamento entre linhas e população de plantas, no teste $\mathrm{F}$ da análise de variância, os valores obtidos não foram significativos somente para o estádio fenológico correspondente a $\mathrm{V}_{7}$. 
Tabela 1. Variáveis climáticas observadas em Piracicaba, SP, de dezembro de 2001 a abril de 2002

\begin{tabular}{|c|c|c|c|c|c|c|c|}
\hline \multirow{2}{*}{$\begin{array}{l}\text { Fenologia }\left({ }^{1}\right) \\
\text { Fases }\end{array}$} & \multirow{2}{*}{ Períodos } & \multirow{2}{*}{ N. ${ }^{\circ}$ de dias } & \multirow{2}{*}{$\begin{array}{c}\text { Radiação solar } \\
\text { total }\end{array}$} & \multirow{2}{*}{$\begin{array}{c}\text { Precipitação } \\
\text { total }\end{array}$} & \multicolumn{3}{|c|}{ Temperatura média } \\
\hline & & & & & Máxima & Mínima & Média \\
\hline & & & $\mathrm{cal} \mathrm{cm} \mathrm{cm}^{-2} \cdot \mathrm{d}$ & $\mathrm{mm}$ & 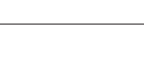 & ${ }^{\circ} \mathrm{C}-$ & \\
\hline \multirow[t]{3}{*}{$S-Q C$} & $4 / 12 / 01$ & & & & & & \\
\hline & $\mathrm{a}$ & 36 & 15079,0 & 283,9 & 29,6 & 19,2 & 23,2 \\
\hline & $9 / 1 / 02$ & & & & & & \\
\hline \multirow[t]{3}{*}{$\mathrm{QC}-\mathrm{R}_{1}$} & $9 / 1 / 02$ & & & & & & \\
\hline & $\mathrm{a}$ & 24 & 9558,0 & 230,9 & 29,5 & 19,4 & 23,0 \\
\hline & $2 / 2 / 02$ & & & & & & \\
\hline \multirow[t]{3}{*}{$\mathrm{R}_{1}-\mathrm{R}_{5}$} & $2 / 2 / 02$ & & & & & & \\
\hline & $\mathrm{a}$ & 33 & 13756,0 & 165,5 & 29,8 & 18,6 & 23,3 \\
\hline & $7 / 3 / 02$ & & & & & & \\
\hline \multirow[t]{3}{*}{$\mathrm{R}_{5}-\mathrm{R}_{8}$} & $7 / 3 / 02$ & & & & & & \\
\hline & $\mathrm{a}$ & 50 & 21494,0 & 255,4 & 36,2 & 21,3 & 28,7 \\
\hline & $26 / 4 / 02$ & & & & & & \\
\hline Totais & - & 143 & 59887,0 & 935,7 & - & - & - \\
\hline Médias & - & - & - & - & 31,3 & 19,6 & 24,6 \\
\hline
\end{tabular}

$\left({ }^{1}\right) \mathrm{S}-\mathrm{QC}=$ semeadura à queda dos cotilédones. $\mathrm{QC}-\mathrm{R}_{1}=$ queda dos cotilédones ao início do florescimento. $\mathrm{R}_{1}-\mathrm{R}_{5}=$ início do florescimento ao início da granação. $R_{5}-R_{8}=$ início da granação à maturidade a campo.

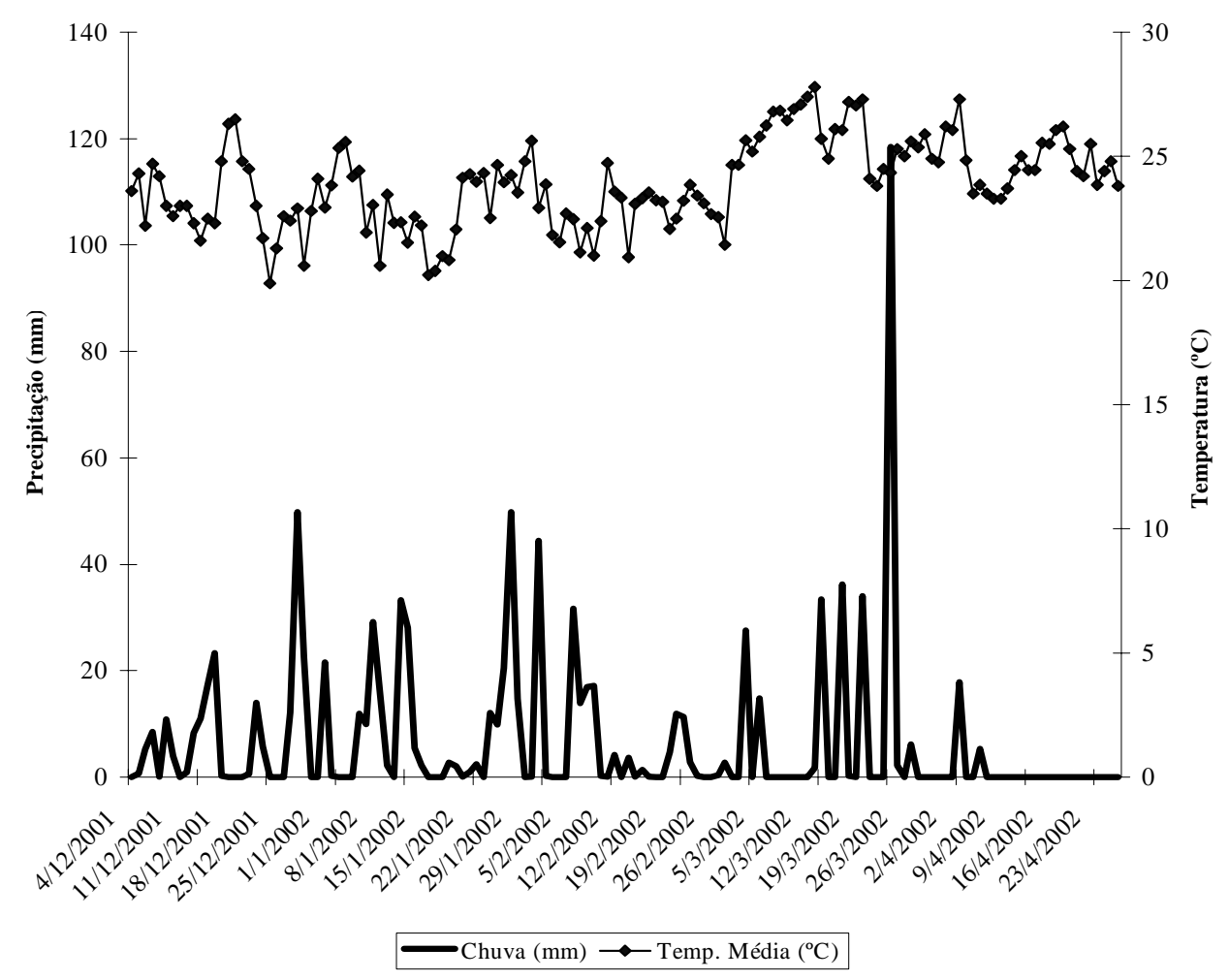

Figura 1. Distribuição pluvial e temperatura média diária do ar, durante o período de experimentação em campo. Piracicaba (SP), 2002. 
Para a variável índice de área foliar (IAF), na análise de variância foram obtidos valores significativos para os fatores espaçamento entre linhas e população de plantas para todas as leituras efetuadas. Com relação à interação dos fatores espaçamento entre linhas e população de plantas, no teste $\mathrm{F}$ da análise de variância os valores obtidos foram significativos somente para as leituras efetuadas nos estádios fenológicos $V_{9} / R_{1}$ e $R_{6}$, realizadas, respectivamente, em 2 de fevereiro e 28 de março de 2002.

\subsection{Fechamento nas entrelinhas}

Pelos dados da tabela 2, verifica-se o nãofechamento total das entrelinhas para os tratamentos nos quais o espaçamento entre linhas foi de $0,70 \mathrm{~m}$. Também, pode-se verificar que, nos tratamentos com 0,60 $\mathrm{m}$ de espaçamento entre linhas, foi necessário um tempo maior para $100 \%$ do fechamento nas entrelinhas.

Com o fechamento nas entrelinhas, nos estádios iniciais da cultura da soja, possibilita-se às plantas o desenvolvimento precoce do seu aparato fotossintético. PIres et al. (1998) estudando a cultivar FT-Saray, em dois espaçamentos, obtiveram, no estádio $\mathrm{V}_{6}$, aos 34 dias após a emergência, $72 \%$ e $55 \%$ de fechamento nas entrelinhas, respectivamente, nos espaçamentos de 0,20 e 0,40 m entre linhas; no estádio $\mathrm{R}_{2}$, obtiveram, em ambos os espaçamentos, $100 \%$ de fechamento nas entrelinhas.

As porcentagens de fechamento nas entrelinhas nos estádios fenológicos $V_{7}, R_{1}, R_{2}, R_{3}, R_{5}$ e $R_{6}$, também, estão esquematicamente apresentadas em função do tempo de fechamento nas entrelinhas, na figura 2. Para os tratamentos referentes à população de 70.000 plantas por hectare, verificouse que, somente naqueles com espaçamento de 0,20 $\mathrm{m}$, o fechamento nas entrelinhas foi equivalente a $100 \%$. No espaçamento de $0,70 \mathrm{~m}$, nessa mesma população, o fechamento nas entrelinhas foi ao redor de $50 \%$, propiciando-se emergência, desenvolvimento e crescimento de uma gama razoável de plantas daninhas, competidoras diretas com a soja, com as quais, não manejadas, poderiam ser acarretadas reduções na produtividade agrícola (Figura 2a).

Como se pode observar na figura 2, em alguns tratamentos foi proporcionado total fechamento nas entrelinhas, em menor espaço de tempo, como naqueles com 0,20 e $0,30 \mathrm{~m}$ entre linhas e população de $210.000,280.000$ e 350.000 plantas por hectare. Com esse rápido fechamento nas entrelinhas são estabelecidas condições de menor circulação de ar e de maior umidade, o que pode favorecer a incidência de doenças.

$\mathrm{Na}$ figura $2 \mathrm{~b}$, verifica-se que, para a população de 140.000 plantas por hectare, nos espaçamentos de 0,60 e 0,70 $\mathrm{m}$, houve problemas quanto ao tempo de fechamento, muito longo, além de não ser total, mas $78 \%$ e $60 \%$ respectivamente. O mesmo ocorreu para as populações de 210.000 e 280.000 plantas por hectare, porém, com resultados mais favoráveis de fechamento nas entrelinhas. Para a população de 350.000 plantas por hectare, observouse o menor tempo de fechamento nas entrelinhas, com altas porcentagens (Figura 2e).

Tabela 2. Fechamento nas entrelinhas em diferentes espaçamentos e períodos fenológicos na cultura da soja, cultivar Conquista. Piracicaba (SP), janeiro a março de 2002

\begin{tabular}{|c|c|c|c|c|c|c|c|}
\hline \multirow{2}{*}{$\begin{array}{l}\text { Espaçamento } \\
\text { entre linhas }\end{array}$} & \multicolumn{7}{|c|}{ Porcentagem de fechamento das entrelinhas } \\
\hline & $\begin{array}{l}25 / 1 \\
\left(V_{7}\right)\end{array}$ & $\begin{array}{c}2 / 2 \\
\left(V_{9} / R_{1}\right)\end{array}$ & $\begin{array}{l}7 / 2 \\
\left(\mathrm{R}_{2}\right)\end{array}$ & $\begin{array}{c}15 / 2 \\
\left(\mathrm{R}_{3}\right)\end{array}$ & $\begin{array}{l}7 / 3 \\
\left(R_{5}\right)\end{array}$ & $\begin{array}{c}14 / 3 \\
\left(\mathrm{R}_{5} / \mathrm{R}_{6}\right)\end{array}$ & $\begin{array}{l}22 / 3 \\
\left(R_{6}\right)\end{array}$ \\
\hline \multicolumn{8}{|l|}{$\bar{m}$} \\
\hline 0,20 & 81,8 a & $90,0 \mathrm{a}$ & 93,7 a & $100,0 \mathrm{a}$ & $100,0 \mathrm{a}$ & $100,0 \mathrm{a}$ & $100,0 \mathrm{a}$ \\
\hline 0,30 & $69,0 \mathrm{ab}$ & $83,3 \mathrm{ab}$ & 91,7 a & 98,7 a & $100,0 \mathrm{a}$ & $100,0 \mathrm{a}$ & 100,0 a \\
\hline 0,40 & $65,3 \mathrm{ab}$ & $82,1 \mathrm{ab}$ & 89,0 a & 96,9 a & $99,2 \mathrm{a}$ & $100,0 \mathrm{a}$ & 100,0 a \\
\hline 0,50 & 55,9 bc & $76,4 \mathrm{~b}$ & 87,9 a & 93,6 a & $96,1 \mathrm{ab}$ & 99,7 a & 99,7 a \\
\hline 0,60 & $42,1 \mathrm{~cd}$ & $63,3 \mathrm{c}$ & $71,7 \mathrm{~b}$ & $82,9 \mathrm{~b}$ & $88,9 \mathrm{~b}$ & 97,6 a & 97,6 a \\
\hline 0,70 & $35,2 \mathrm{~d}$ & $54,1 \mathrm{c}$ & $62,3 \mathrm{~b}$ & $74,0 \mathrm{~b}$ & 78,8 с & 90,6 b & $91,0 \mathrm{~b}$ \\
\hline D.M.S. & 17,6 & 12,1 & 16,2 & 10,3 & 9,0 & 4,2 & 4,0 \\
\hline C.V. (\%) & 10,7 & 5,7 & 6,9 & 4,0 & 3,4 & 1,5 & 1,4 \\
\hline
\end{tabular}

Médias seguidas por letras distintas são diferentes entre si pelo teste de Tukey ao nível de significância de 5\%. 
Pop. 210.000 pls/ha

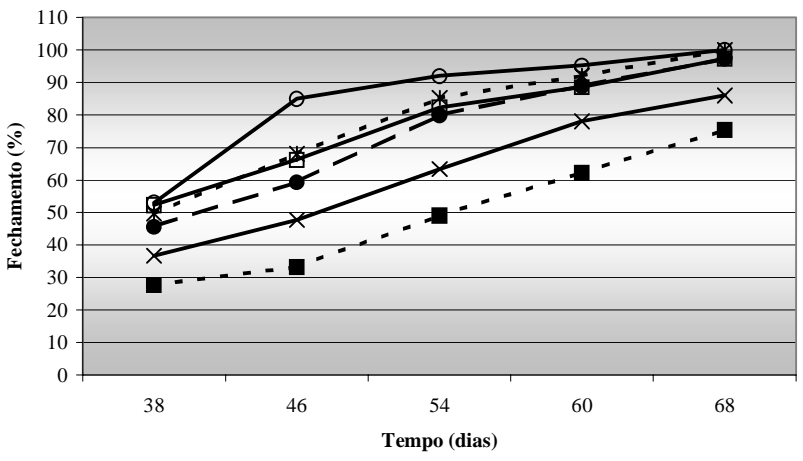

- *- Esp. 0,30 m Dens. $6,3 \mathrm{pl} / \mathrm{m}$ - - Esp. 0,50 m Dens. $10,5 \mathrm{pl} / \mathrm{m}$
Pop. 280.000 pls/ha

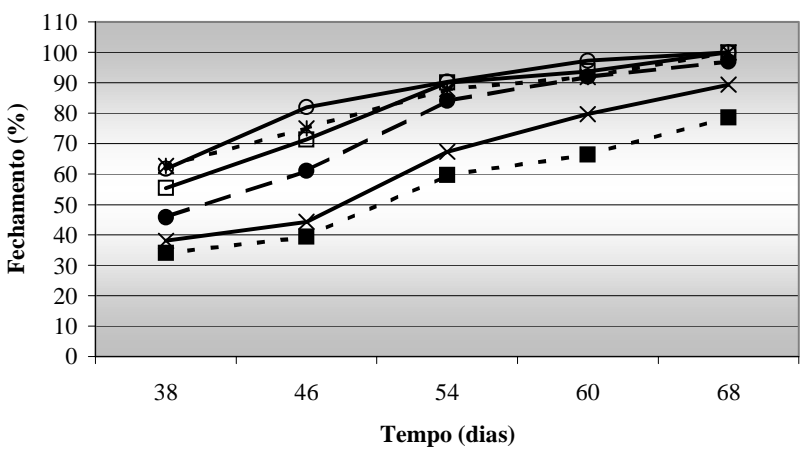

-Esp. 0,20 m Dens. $5,6 \mathrm{pl} / \mathrm{m}$ 廿-Esp. $0,40 \mathrm{~m}$ Dens. $11,2 \mathrm{pl} / \mathrm{m}$ *- Esp. 0,30 m Dens. $8,4 \mathrm{pl} / \mathrm{m}$ $\longrightarrow$-Esp. 0,50 m Dens. $14,0 \mathrm{pl} / \mathrm{m}$

Pop. 350.000 pls/ha

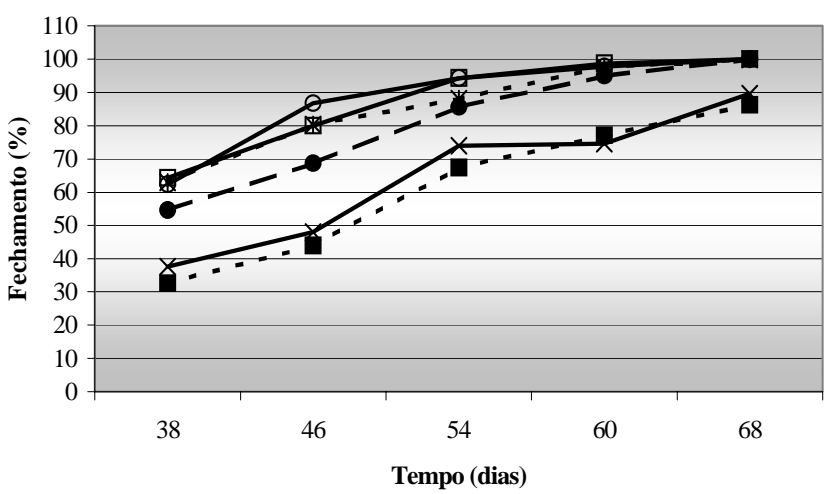

Esp. 0,20 m Dens. $7,0 \mathrm{pl} / \mathrm{m}$ —Esp. 0,40 m Dens. $14,0 \mathrm{pl} / \mathrm{m}$

- * - Esp. 0,30 m Dens. $10,5 \mathrm{pl} / \mathrm{m}$

- Esp. $0,50 \mathrm{~m}$ Dens. $17,5 \mathrm{pl} / \mathrm{m}$

Pop. 70.000 pls/ha

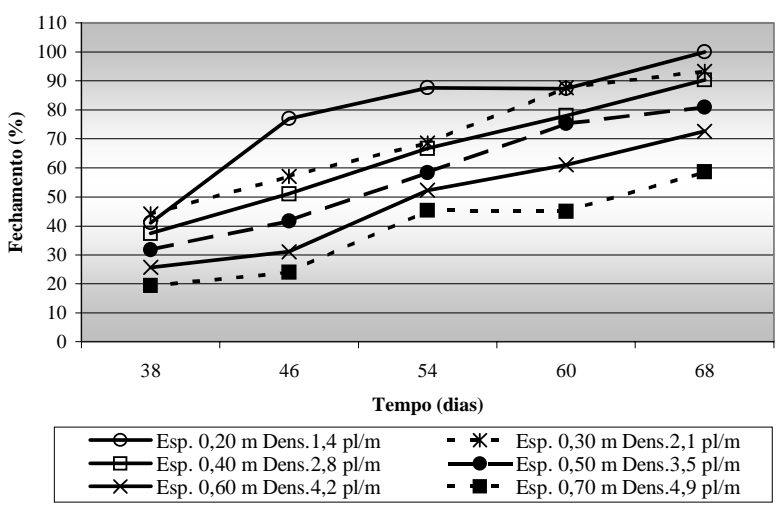

Pop. $140.000 \mathrm{pls} / \mathrm{h}$

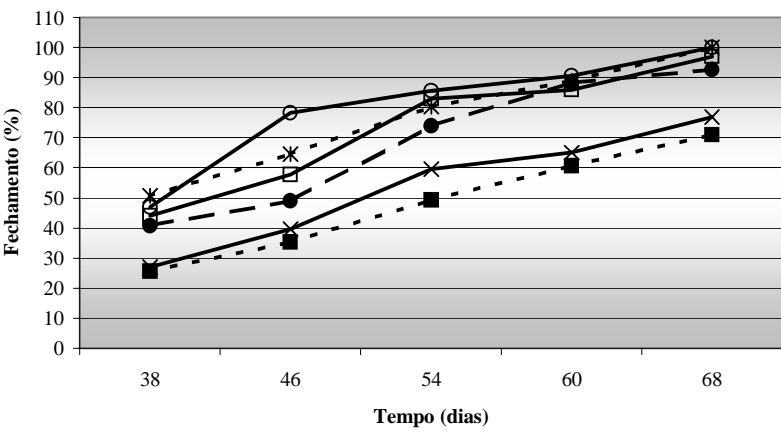

-Esp. $0,20 \mathrm{~m}$ Dens. $2,8 \mathrm{pl} / \mathrm{m}$ - * - Esp. $0,30 \mathrm{~m}$ Dens. $4,2 \mathrm{pl} / \mathrm{m}$ - Esp. 0,40 m Dens. $5,6 \mathrm{pl} / \mathrm{m}$ - Esp. 0,50m Dens $7,0 \mathrm{pl} / \mathrm{m}$

Figura 2. Tempo em dias após a emergência e porcentagem de fechamento entrelinhas, na cultivar de soja Conquista, em cinco populações de plantas e seis espaçamentos entrelinhas. Piracicaba (SP), 2002. 


\section{2 Índice de área foliar}

Na tabela 3 e figura 3, observam-se os maiores IAF, na cultivar Conquista, entre os estádios fenológicos $R_{4}$ e $R_{6}$, para a média das cinco populações de plantas, sendo este mais pronunciado entre os estádios $R_{4}$ e $R_{5}$, nos menores espaçamentos $(£ 0,50 \mathrm{~m})$ e, entre $R_{5}$ e $R_{6}$, nos maiores espaçamentos $(0,60$ e $0,70 \mathrm{~m})$. PORRAs et al. (1997) constataram IAF máximo no estádio fenológico correspondente à formação das vagens $\left(R_{3}\right)$ e GoNZÁlEz et al. (1988), no estádio fenológico $R_{5}$, correspondente ao início da granação, sendo então decrescente em decorrência da perda de folhas por senescência. GAZZONI (1974) afirma serem os estádios de $R_{2} / R_{3}$ como os de máximo IAF, porém, conforme resultados obtidos por Pеiхото (1998), houve, em geral, aumento linear do IAF após o período de crescimento inicial lento até a formação completa das vagens, no estádio $\mathrm{R}_{4}$. GonZÁlez et al. (1988) descreveram os maiores valores numéricos de IAF por ocasião do início da granação das vagens (estádio $\mathrm{R}_{5}$ ), para todos os espaçamentos entre linhas, com exceção ao espaçamento de $0,70 \mathrm{~m}$, no qual o maior valor numérico de IAF foi entre os estádios $R_{5}$ e $\mathrm{R}_{6}$ (Tabela 3).

O fato de o IAF máximo ser verificado no estádio $R_{5}$ é de relevante significância fisiológica para a cultura da soja. A partir do início da granação das vagens, intensifica-se a demanda da planta por água, nutrientes e fotoassimilados. Esses fatores, essenciais à produção, são preferencialmente direcionados aos grãos em formação, não só para atendimento do acúmulo crescente de matéria seca, mas também, da biossíntese de óleo e de proteína nas sementes.
Shibles e Weber (1965) também referenciaram o auge do IAF por ocasião do fim da frutificação e início da granação da soja, além de terem constatado dois picos de atividade fotossintética: o primeiro por ocasião do pleno florescimento da soja, para atender o pegamento floral; o segundo, por ocasião do início da granação, quando a presença de fotoassimilados se faz necessária ao desenvolvimento das vagens e dos grãos no seu interior.

Constatou-se interação diferenciada entre espaçamento entre linhas e as diferentes populações de plantas, nos diferentes estádios fenológicos avaliados. Os maiores IAFs foram observados nos tratamentos referentes às maiores populações, ou seja, 280.000 e 350.000 plantas por hectare (Figuras 3d e 3e).

Observa-se que, na medida em que é aumentado o espaçamento entre linhas, há diminuição no índice de área foliar, porém, não sendo estatisticamente significativo em todos os estádios da cultura. PIRES et al. (1998), por exemplo, constataram valores menores de IAF no espaçamento de $0,40 \mathrm{~m}$, do que no de $0,20 \mathrm{~m}$ entre linhas.

\subsection{Produtividade agrícola}

Os resultados para a produtividade agrícola são apresentados na tabela 4 , e em seis tratamentos foram obtidas produtividades superiores a $2.600 \mathrm{~kg}$ $\mathrm{ha}^{-1}$, porém sem diferenças estatísticas entre si e os demais, a saber: T14 com 2.740,1 kg ha ${ }^{-1}(280.000$ plantas ha-1); T20 com 2.677,3 kg ha ${ }^{-1}(350.000$ plantas ha-1); T15 com 2.663,5 kg ha ${ }^{-1}(350.000$ plantas ha-1); T7 com 2.659,9 kg ha ${ }^{-1}$ (140.000 plantas $\left.\mathrm{ha}^{-1}\right)$; T9 com 2.635,3 kg ha-1 (280.000 plantas ha $\left.{ }^{-1}\right)$ e T10 com 2.608,3 $\mathrm{kg} \mathrm{ha}^{-1}$ (350.000 plantas ha $\left.{ }^{-1}\right)$.

Tabela 3. Índice de área foliar da soja, cultivar Conquista. Piracicaba (SP), janeiro a abril de 2002

\begin{tabular}{|c|c|c|c|c|c|c|c|c|c|c|}
\hline \multirow[b]{2}{*}{$\begin{array}{l}\text { Espaçamento } \\
\text { entre linhas }\end{array}$} & \multicolumn{10}{|c|}{ Índice de área foliar } \\
\hline & $\begin{array}{l}25 / 1 \\
\left(V_{7}\right)\end{array}$ & $\begin{array}{c}2 / 2 \\
\left(\mathrm{~V}_{9} / \mathrm{R}_{1}\right)\end{array}$ & $\begin{array}{c}13 / 2 \\
\left(\mathrm{R}_{2}\right)\end{array}$ & $\begin{array}{c}20 / 2 \\
\left(\mathrm{R}_{2} / \mathrm{R}_{3}\right)\end{array}$ & $\begin{array}{c}28 / 2 \\
\left(\mathrm{R}_{4} / \mathrm{R}_{5}\right)\end{array}$ & $\begin{array}{l}7 / 3 \\
\left(\mathrm{R}_{5}\right)\end{array}$ & $\begin{array}{c}14 / 3 \\
\left(R_{5} / R_{6}\right)\end{array}$ & $\begin{array}{l}22 / 3 \\
\left(R_{6}\right)\end{array}$ & $\begin{array}{l}28 / 3 \\
\left(R_{6}\right)\end{array}$ & $\begin{array}{l}4 / 4 \\
\left(\mathrm{R}_{6}\right)\end{array}$ \\
\hline \multicolumn{11}{|l|}{$\mathrm{m}$} \\
\hline 0,20 & $0,8 \mathrm{a}$ & $1,1 \mathrm{a}$ & $1,5 \mathrm{ab}$ & $2,2 \mathrm{ab}$ & $2,7 \mathrm{a}$ & $3,1 \mathrm{a}$ & $2,8 \mathrm{a}$ & $2,3 \mathrm{a}$ & $2,5 \mathrm{a}$ & $2,0 \mathrm{a}$ \\
\hline 0,30 & $0,5 \mathrm{a}$ & $0,9 \mathrm{a}$ & $1,5 \mathrm{ab}$ & $2,2 \mathrm{ab}$ & $2,8 \mathrm{a}$ & $3,0 \mathrm{a}$ & $2,8 \mathrm{a}$ & $2,4 \mathrm{a}$ & $2,6 \mathrm{a}$ & $2,0 \mathrm{a}$ \\
\hline 0,40 & $0,7 \mathrm{a}$ & $1,2 \mathrm{a}$ & $1,8 \mathrm{a}$ & $2,6 \mathrm{a}$ & $3,0 \mathrm{a}$ & $3,2 \mathrm{a}$ & $2,9 \mathrm{a}$ & $2,4 \mathrm{a}$ & $2,6 \mathrm{a}$ & $2,0 \mathrm{a}$ \\
\hline 0,50 & 0,6 a & $1,0 \mathrm{a}$ & $1,6 \mathrm{ab}$ & $2,4 \mathrm{ab}$ & $2,8 \mathrm{a}$ & $2,9 \mathrm{a}$ & $2,8 \mathrm{a}$ & $2,3 \mathrm{a}$ & $2,4 \mathrm{ab}$ & $1,8 \mathrm{ab}$ \\
\hline 0,60 & $0,6 \mathrm{a}$ & $0,7 \mathrm{a}$ & $1,1 \mathrm{ab}$ & $1,6 \mathrm{bc}$ & $2,0 \mathrm{ab}$ & $2,5 \mathrm{ab}$ & $2,3 \mathrm{ab}$ & $2,0 \mathrm{ab}$ & $2,1 \mathrm{ab}$ & $1,6 \mathrm{ab}$ \\
\hline 0,70 & 0,6 a & $0,6 \mathrm{a}$ & $0,8 \mathrm{~b}$ & $1,0 \mathrm{c}$ & $1,5 \mathrm{~b}$ & $1,7 \mathrm{~b}$ & $1,8 \mathrm{~b}$ & $1,6 \mathrm{~b}$ & $1,7 \mathrm{~b}$ & $1,4 \mathrm{~b}$ \\
\hline D.M.S. & 0,6 & 0,8 & 0,9 & 1,0 & 1,1 & 0,9 & 0,8 & 0,5 & 0,7 & 0,5 \\
\hline C.V. (\%) & 32,0 & 29,7 & 22,9 & 17,4 & 16,3 & 11,2 & 11,4 & 7,5 & 10,8 & 9,2 \\
\hline
\end{tabular}

Médias seguidas por letras distintas são diferentes entre si pelo teste de Tukey ao nível de significância de 5\%. 
Pop. $70.000 \mathrm{pls} / \mathrm{ha}$

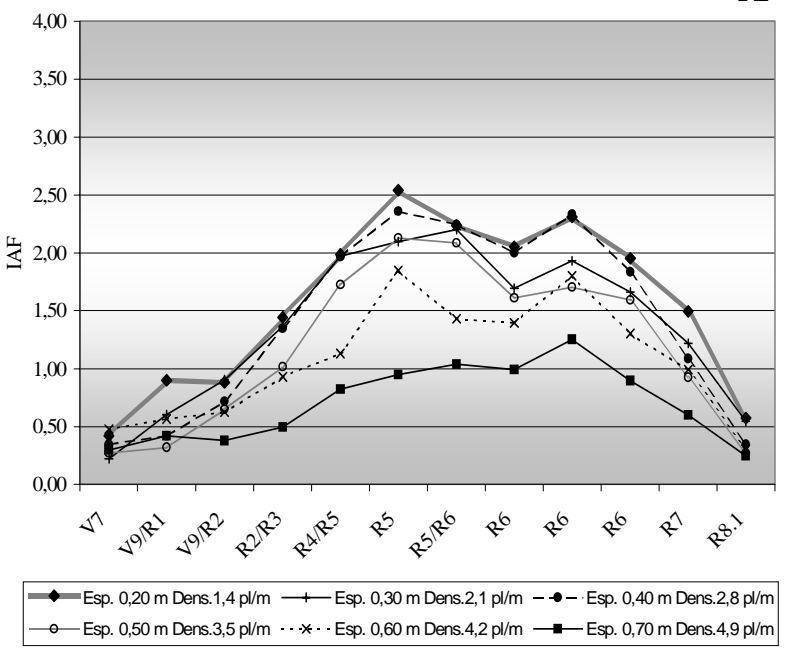

Pop. $210.000 \mathrm{pls} / \mathrm{ha}$

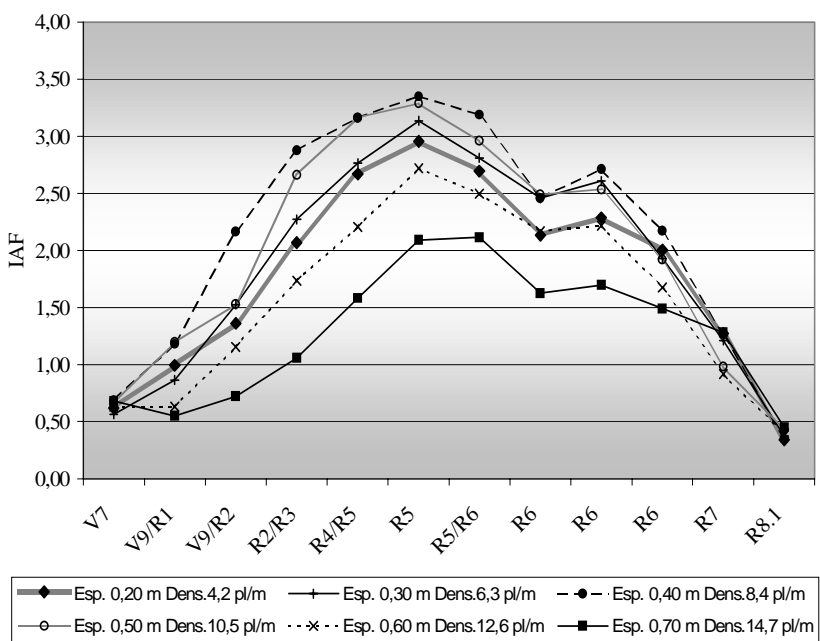

Pop. $140.000 \mathrm{pls} / \mathrm{ha}$

B

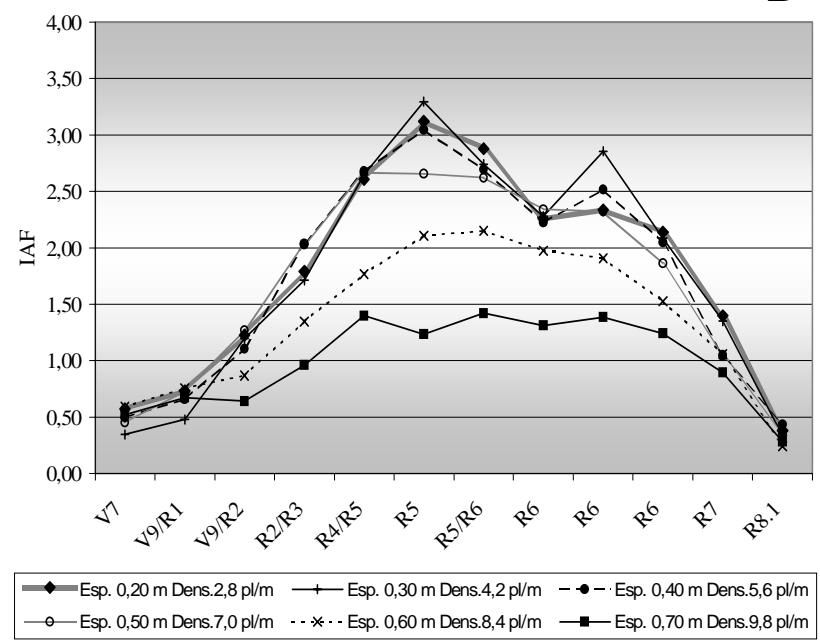

Pop. $280.000 \mathrm{pls} / \mathrm{ha}$

D

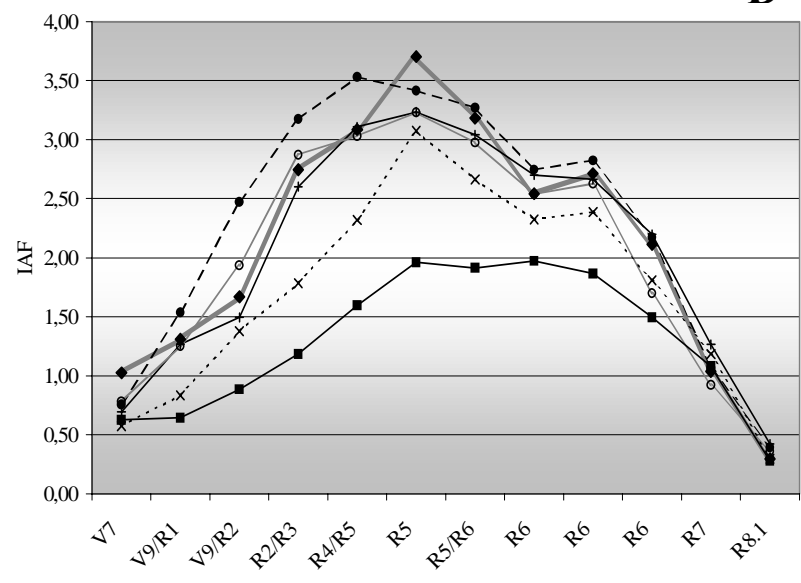

$\longrightarrow$ Esp. 0,20 m Dens.5,6 pl/m ——Esp. 0,30 m Dens. $8,4 \mathrm{pl} / \mathrm{m}$ - - Esp. $0,40 \mathrm{~m}$ Dens. $11,2 \mathrm{pl} / \mathrm{m}$ ——Esp. $0,50 \mathrm{~m}$ Dens. $14,0 \mathrm{pl} / \mathrm{m} \cdots * \cdots$ Esp. $0,60 \mathrm{~m}$ Dens. $16,8 \mathrm{pl} / \mathrm{m} \longrightarrow$ —Esp. $0,70 \mathrm{~m}$ Dens. $19,6 \mathrm{pl} / \mathrm{m}$

Pop. $350.000 \mathrm{pls} / \mathrm{ha}$

$\mathbf{E}$

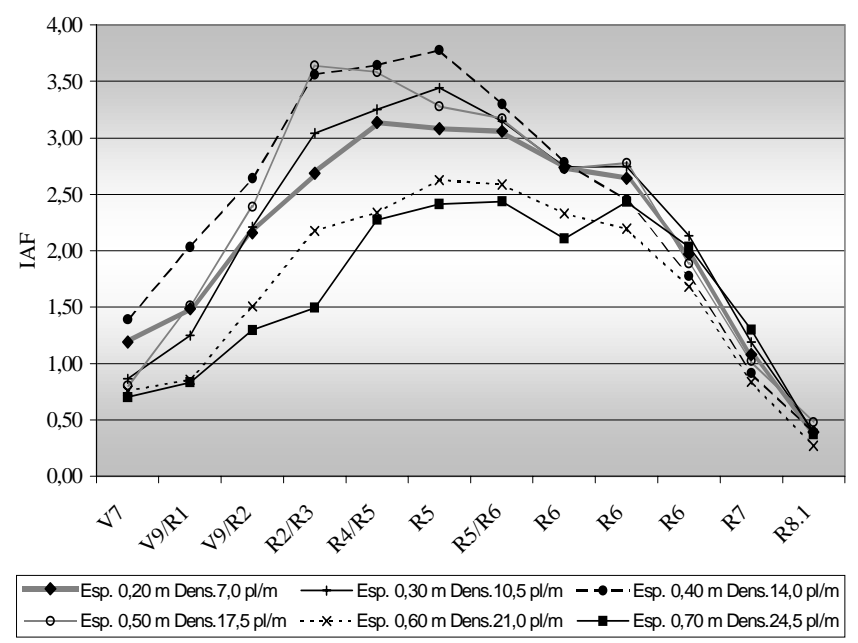

Figura 3. Índice de área foliar (IAF) da cultivar de soja Conquista, em vários estádios fenológicos, em cinco populações de plantas e seis espaçamentos entrelinhas. Piracicaba (SP), 2002. 
Nota-se crescimento proporcional da produtividade agrícola com o aumento da população de plantas e, em cada grupo populacional, destacase o espaçamento de $0,30 \mathrm{~m}$ entre linhas, com exceção para a menor população de plantas de soja por hectare. Em seguida, destaca-se o espaçamento de 0,40 m entre linhas, principalmente, nas populações de 70.000,
280.000 e 350.000 plantas por hectare, respectivamente, com as densidades de 2,8; 11,2 e 14,0 plantas por metro de linha.

Estatisticamente, não foram constatadas diferenças significativas entre os espaçamentos entre linhas, para massa de mil grãos e produtividade agrícola (Tabela 4).

Tabela 4. Produtividade agrícola e massa de mil grãos de soja, cv. Conquista, em função da população. Piracicaba (SP), 2002

\begin{tabular}{|c|c|c|c|c|c|}
\hline Tratamentos & Espaçamento & Densidade & População & Produtividade agrícola & Massa de mil grãos \\
\hline & $\mathrm{m}$ & $\mathrm{pl} \mathrm{m}{ }^{-1}$ & pl ha ${ }^{-1}$ & $\mathrm{~kg} \mathrm{ha}^{-1}$ & $\mathrm{~g}$ \\
\hline $\mathrm{T} 1$ & 0,20 & 1,4 & 70.000 & $1818,2 \mathrm{a}$ & $182,9 \mathrm{ab}$ \\
\hline T6 & 0,30 & 2,1 & 70.000 & 1699,8 a & $180,5 \mathrm{~b}$ \\
\hline T11 & 0,40 & 2,8 & 70.000 & $2256,3 \mathrm{a}$ & 201,3 a \\
\hline T16 & 0,50 & 3,5 & 70.000 & $2072,5 \mathrm{a}$ & $188,7 \mathrm{ab}$ \\
\hline $\mathrm{T} 21$ & 0,60 & 4,2 & 70.000 & 1956,8 a & $186,2 \mathrm{ab}$ \\
\hline \multirow[t]{2}{*}{$\mathrm{T} 26$} & 0,70 & 4,9 & 70.000 & $1533,4 \mathrm{a}$ & $183,8 \mathrm{ab}$ \\
\hline & Média & & & 1889,5 & 187,2 \\
\hline $\mathrm{T} 2$ & 0,20 & 2,8 & 140.000 & $2366,1 \mathrm{a}$ & 182,9 a \\
\hline $\mathrm{T} 7$ & 0,30 & 4,2 & 140.000 & 2659,9 a & 183,5 a \\
\hline T12 & 0,40 & 5,6 & 140.000 & 2478,8 a & $182,6 \mathrm{a}$ \\
\hline $\mathrm{T} 17$ & 0,50 & 7,0 & 140.000 & 2531,0 a & $180,9 \mathrm{a}$ \\
\hline $\mathrm{T} 22$ & 0,60 & 8,4 & 140.000 & $2114,0 \mathrm{a}$ & 183,7 a \\
\hline \multirow[t]{2}{*}{$\mathrm{T} 27$} & 0,70 & 9,8 & 140.000 & 2058,6 a & 186,0 a \\
\hline & Média & & & 2368,1 & 183,3 \\
\hline $\mathrm{T} 3$ & 0,20 & 4,2 & 210.000 & 2261,9 a & 181,8 a \\
\hline T8 & 0,30 & 6,3 & 210.000 & $2296,1 \mathrm{a}$ & $179,0 \mathrm{a}$ \\
\hline $\mathrm{T} 13$ & 0,40 & 8,4 & 210.000 & 2295,4 a & $186,9 \mathrm{a}$ \\
\hline T18 & 0,50 & 10,5 & 210.000 & 2529,4 a & $183,3 \mathrm{a}$ \\
\hline $\mathrm{T} 23$ & 0,60 & 12,6 & 210.000 & 1972,2 a & 180,4 a \\
\hline \multirow[t]{2}{*}{$\mathrm{T} 28$} & 0,70 & 14,7 & 210.000 & 2174,0 a & 181,6 a \\
\hline & Média & & & 2254,8 & 182,2 \\
\hline $\mathrm{T} 4$ & 0,20 & 5,6 & 280.000 & 2376,4 a & $182,2 \mathrm{a}$ \\
\hline T9 & 0,30 & 8,4 & 280.000 & $2635,3 \mathrm{a}$ & $185,2 \mathrm{a}$ \\
\hline $\mathrm{T} 14$ & 0,40 & 11,2 & 280.000 & $2740,1 \mathrm{a}$ & $185,0 \mathrm{a}$ \\
\hline T19 & 0,50 & 14,0 & 280.000 & 2263,8 a & $180,3 \mathrm{a}$ \\
\hline $\mathrm{T} 24$ & 0,60 & 16,8 & 280.000 & $2145,3 \mathrm{a}$ & 183,6 a \\
\hline \multirow[t]{2}{*}{$\mathrm{T} 29$} & 0,70 & 19,6 & 280.000 & $2201,0 \mathrm{a}$ & 175,9 a \\
\hline & Média & & & 2393,7 & 182,0 \\
\hline T5 & 0,20 & 7,0 & 350.000 & $2233,4 \mathrm{a}$ & 177,4 a \\
\hline $\mathrm{T} 10$ & 0,30 & 10,5 & 350.000 & $2608,3 \mathrm{a}$ & $182,3 \mathrm{a}$ \\
\hline $\mathrm{T} 15$ & 0,40 & 14,0 & 350.000 & $2663,5 \mathrm{a}$ & 183,2 a \\
\hline T20 & 0,50 & 17,5 & 350.000 & 2677,3 a & $186,4 \mathrm{a}$ \\
\hline $\mathrm{T} 25$ & 0,60 & 21,0 & 350.000 & 2091,7 a & 181,6 a \\
\hline \multirow[t]{3}{*}{ T30 } & 0,70 & 24,5 & 350.000 & $2549,1 \mathrm{a}$ & 185,6 a \\
\hline & Média & & & 2470,6 & 182,8 \\
\hline & C.V.(\%) & & & 12,1 & 4,4 \\
\hline
\end{tabular}

Médias seguidas por letras distintas são diferentes entre si pelo teste de Tukey ao nível de significância de 5\%. 
O efeito da população na massa de grãos é variável. VAl et al. (1971), dentre outros pesquisadores, afirmam que não há variação na massa de mil sementes com a mudança na densidade de plantas na linha. Weber et al. (1966) obtiveram aumento dessa característica relacionado ao aumento da população de plantas. Peixoto (1998) verificou resultados em que, com o aumento da densidade de plantas na linha houve incremento da massa de grãos.

Apenas para a população de 70.000 plantas por hectare, no arranjo espacial estabelecido com o espaçamento entre linhas de $0,40 \mathrm{~m}$ com 2,8 plantas por metro de linha, proporcionou-se maior produtividade numérica agrícola $\left(2.256,3 \mathrm{~kg} \mathrm{ha}^{-1}\right)$ e a maior massa de mil grãos $(201,3 \mathrm{~g})$, significativamente superior à massa de mil grãos proporcionada pela combinação de $0,30 \mathrm{~m}$ entre linhas com 2,1 plantas por metro de linha.
Na média das cinco populações houve aumento numérico nos valores de massa de mil grãos e da produtividade agrícola, do menor espaçamento entre linhas $(0,20 \mathrm{~m})$ para os espaçamentos intermediários $(0,40$ e $0,50 \mathrm{~m})$, com decréscimo nos maiores espaçamentos entre fileiras de plantas $(0,60$ e $0,70 \mathrm{~m}$ ) (Tabela 5). Provavelmente, haja competição entre plantas nos menores espaçamentos, em vista dos fatores ambientais, com diminuição na massa dos grãos. As menores produtividades obtidas nos maiores espaçamentos talvez sejam decorrentes de menor IAF e de pequeno número de indivíduos por unidade de área. As menores densidades obtidas nas menores populações combinadas aos maiores espaçamentos, ficaram abaixo do limite de compensação e crescimento lateral pelas plantas e, conseqüentemente, abaixo do nível mínimo necessário de captação de luz incidente necessária para a maximização da produtividade agrícola.

Tabela 5. Produtividade agrícola e massa de mil grãos, cv. Conquista, em função do espaçamento entre linhas. Piracicaba (SP), 2002

\begin{tabular}{lcc}
\hline Espaçamentos entre linhas & Massa de mil grãos & Produtividade agrícola \\
\hline $\mathrm{m}$ & $\mathrm{g}$ & $\mathrm{kg} \mathrm{ha}^{-1}$ \\
0,20 & $2211,2 \mathrm{a}$ & $181,4 \mathrm{a}$ \\
0,30 & $2379,9 \mathrm{a}$ & $182,1 \mathrm{a}$ \\
0,40 & $2486,8 \mathrm{a}$ & $187,8 \mathrm{a}$ \\
0,50 & $2414,8 \mathrm{a}$ & $183,9 \mathrm{a}$ \\
0,60 & $2056,0 \mathrm{a}$ & $183,1 \mathrm{a}$ \\
0,70 & $2103,2 \mathrm{a}$ & $182,6 \mathrm{a}$ \\
D.M.S. & 737,7 & 9,4 \\
C.V. (\%) & 11,4 & 1,8 \\
\hline
\end{tabular}

Médias seguidas por letras distintas são diferentes entre si pelo teste de Tukey ao nível de significância de $5 \%$.

\section{CONCLUSÕES}

1. O índice de área foliar da cultivar MG/BR 46 (Conquista) é máximo no estádio fenológico correspondente ao início da granação das vagens $\left(R_{5}\right)$, nos espaçamentos de 0,20 a 0,60 m entre linhas.

2. A cultivar MG/BR 46 (Conquista) tem alta plasticidade, sendo o índice de área foliar aumentado proporcionalmente com o aumento da população de plantas.

3. O fator de maior influência na velocidade de fechamento entrelinhas para a cultivar MG/BR 46 (Conquista) é o espaçamento.

\section{REFERÊNCIAS}

BARNI, N.A.; GOMES, J.E.S.; GONÇALVES, J.C. Efeito da época de semeadura, espaçamento e população de plantas sobre o desempenho da soja (Glicyne max (L.) Merrill), em solo hidromórfico. Agronomia Sulriograndense, Porto alegre, v. 21, n. 2, p. 245-296, 1985.

BOARD, J.E.; HARVILLE, B.G. Explanations for greater light interception in narrow vs. wide-row soybean. Crop Science, Madison, v. 32, n. 1, p. 198-202, 1992.

BRASIL Ministério da Agricultura e Reforma Agrária. Regras para análise de sementes. Brasília, 1992. 365 p. 
CÂMARA, G.M.S.; HEIFFIG, L.S. Fisiologia, ambiente e rendimento da cultura da soja. In: CÂMARA, G.M.S. Soja: tecnologia da produção. Piracicaba: ESALQ/LPV, 2000. p. 81-120.

EMPRESA BRASILEIRA DE PESQUISA AGROPECUÁRIA. Centro Nacional de Pesquisa da Soja. Recomendações técnicas para a cultura da soja na região Central do Brasil. Londrina: Embrapa, 2000. 245 p.

GAUDÊNCIO, C.A.A.; GAZZIERO, D.L.P.; JASTER, F.; GARCIA, A.; WOBETO, C. População de plantas de soja no sistema de semeadura direta para o Centro-Sul do Estado do Paraná. Londrina: Embrapa, CNPSo, 1990. 4 p. (Comunicado Técnico, 47)

GAZZIERO, D.L.P.; SOUZA, I.F. Manejo integrado de plantas daninhas. In: ARANTES, N.E.; SOUZA, P.I.M. Cultura da soja nos Cerrados. Piracicaba: POTAFOS, 1993. p. 183 - 208.

GAZZONI, D.L. Avaliação do efeito de três níveis de desfolhamento aplicado em quatro estádios de crescimento de dois cultivares de soja (Glycine max (L.) Merrill) sobre a produção e a qualidade do grão. 1974. 70 f. Dissertação (Mestrado) - Faculdade de Agronomia, Universidade Federal do Rio Grande do Sul, Porto Alegre.

GONZÁlEZ, A.; AGUDELO, O.; ROJAS, H. Alteración de las variables fisiológicas de la soya bajo diferentes sistemas de labranza. Palmira: ICA, 1988. 22 p.

MÜLLER, L. Fisiologia. In: MIYASAKA, S.; MEDINA, J.L. A soja no Brasil. Campinas, 1981. p. 109 - 129.

PEIXOTO, C.P.P. Análise de crescimento e rendimento de três cultivares de soja em três épocas de semeadura e três densidades de plantas. 1998. 151 f. Tese (Doutorado) - Escola Superior de Agricultura "Luiz de Queiroz", Universidade de São Paulo, Piracicaba.

PEIXOTO, C.P.; CÂMARA, G. M.S.; MARTINS, M.C.; MARCHIORI, L.F.S.; GUERZONI, R.A.; MATTIAZZI, P. Épocas de semeadura e densidade de plantas de soja: I. Componentes da produção e rendimentos de grãos. Piracicaba: Scientia Agricola, Piracicaba, v. 57, n. 1, p. 89 - 96, 2000.
PIRES, J.L.F.; COSTA, J.A.; THOMAS, A.L. Rendimento de grãos de soja influenciado pelo arranjo de plantas e níveis de adubação. Pesquisa Agropecuária Gaúcha, Porto Alegre, v.4, n. 2, p. 89-92, 1998.

PORRAS, C.A.; CAYÓN, D.G.; DELGADO, O.A. Comportamento fisiologico de genotipos de soya en diferentes arreglos de siembra. Acta Agronómica, Palmira, v. 47, n. 1, p. 9-15, 1997.

SCOTT, W.O.; ALDRICH, S.R. Producción moderna de la soja. Buenos Aires: Hemisferio Sur, 1975. 192 p.

SHAW, R.H.; WEBER, C.R. Effects of canopy arrangements on light interception and yield of soybeans. Agronomy Journal, Madison, v. 59, n. 2, p. 155-159, 1967.

SHIBLES, R.M.; WEBER, C.R. Leaf area, solar radiation interceptation and dry matter production by soybeans. Crop Science, Madison, v. 5, p. 575-577, 1965.

VAL, W.M.C.; BRANDÃO, S.S.; GALVÃO, J.D.; GOMES, F.R. Efeito do espaçamento entre fileiras e da densidade na fileira sobre a produção de grãos e outras características agronômicas da soja (Glycine max (L.) Merrill). Experimentiae, Viçosa, v. 12, n. 12, p. 431 475, dez. 1971 .

WEBER, C.R.; SHIBLES, R.M.; BYTH, D.E. Effect of plant population and row spacing on soybean development and production. Agronomy Journal, Madison, v. 58, p. 99-102, 1966.

WELLS, R. Dynamics of soybean growth in variable planting patterns. Agronomy Journal, Madison, v. 1, n. 81, p. $44-48,1993$

WELLS, R. Soybean growth response to plant density: relationships among photosynthesis, leaf area, and light interception. Crop Science, Madison, v. 31, n. 3, p. 755756, 1991. 